Research Article

\title{
Low-Frequency Vibration Testing of Huge Bucket Wheel Excavator Based on Step-Decay Signals
}

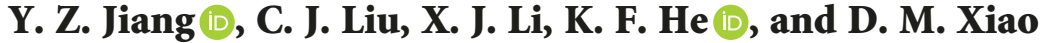 \\ Hunan Provincial Key Laboratory of Health Maintenance for Mechanical Equipment, \\ Hunan University of Science and Technology, Xiangtan 411201, China
}

Correspondence should be addressed to Y. Z. Jiang; jiangyz186@126.com

Received 30 August 2018; Accepted 30 October 2018; Published 2 December 2018

Academic Editor: Salvatore Russo

Copyright (c) 2018 Y. Z. Jiang et al. This is an open access article distributed under the Creative Commons Attribution License, which permits unrestricted use, distribution, and reproduction in any medium, provided the original work is properly cited.

The low-frequency vibration of the bucket wheel excavator has an important impact on the fatigue life of the structures. For conventional vibration testing methods, it is difficult and expensive to excite the overall low-frequency vibration of the whole machine. Hence, in this paper, the excitation method that uses the belt-supporting rollers on the boom as an exciter is tried to excite the low-frequency vibration, so that the low natural frequencies can be identified by Fourier transforming the free decay signals caused by the sudden power off. By this method, the first five natural frequencies are obtained, and the results are verified through corresponding computational numerical model of the bucket wheel excavator. It can be concluded that the proposed testing method can achieve the same accuracy but is much more convenient and costs less than existing methods.

\section{Introduction}

The bucket wheel excavator is a kind of efficient bulk material conveying equipment which is widely used in raw materials storage and transportation yards. The bucked wheel boom is very important for the excavating operation. It weights up to hundreds of tons, length up to tens of meters. Due to the poor working conditions there exist a number of complex excitations, and it is easy to cause the low-frequency vibration of the bucked wheel boom, which induces fatigue cracks and even causes serious accidents such as collapse of the whole machine [1-6]. It is for this reason that bucked wheel excavator requires serving regularly, and abnormal vibration diagnosis and repairments are often performed on the bearing structures $[7,8]$, which has brought huge losses to the plants. Therefore, it is important to study the vibration characteristics of the bucket wheel boom to improve its dynamic properties so that the fatigue life of the structure can be prolonged.

For the dynamic design of the structures, obtaining the natural frequencies is a key and fundamental need. Usually, natural frequencies are based on calculations and numerical simulations while designing, and a lot of work has been carried out on the dynamic modeling of structure and mechanisms for bucket wheel excavators [9, 10]. However, due to the complexity of structures, the calculated ones may differ from real natural frequencies as the computational numerical models do not exactly correspond with real structures, and many details are impropriety simplified. So, it is the quickest and most effective way to obtaining the natural frequency by testing methods. Currently, impulse excitation is a common vibration test method used for natural frequencies testing $[11,12]$, but the power of this kind of excitation is not enough to excite the overall low-frequency vibration. To solve this problem, Gottvald [13] designed a method that frees an initial displacement caused by hanging rope of 26.4 tons in weight at the far end of the bucked wheel boom, so that the natural frequencies can be obtained by Fourier transform of the decay signals caused by the sudden free of initial displacement. Although this method is effective and accurate enough, it is hard for widespread usage because this method is very difficult and expensive. To find an easy and low cost way, in this paper, the excitation method that uses the belt-supporting rollers as exciter is tried for lowfrequency vibration testing of the bucked wheel excavator, and the results prove that this method is much simpler, costs low, and is also effective. 


\section{Test Method}

2.1. Principle. For natural frequency testing by freeing the initial displacement, if there is an initial displacement A, when the initial enforced displacement is released, the motional differential equation of a single-freedom system can be expressed in the form:

$$
\ddot{x}+2 n \dot{x}+\omega^{2} x=\frac{f(t)}{m},
$$

where $2 n=c / m$ and $\omega=\sqrt{k / m}$ in above expression. Since the external force $f(t)$ equals zero in free decay vibration, the solution of equation (1) is

$$
x=A e^{-n t} \sin \left(\sqrt{\omega^{2}-n^{2}} t+\varphi\right) .
$$

Obviously, the vibration displacement $x$ appears as a free decay motion at the natural frequencies $\omega$. If the free decay signal $x$ is measured, it will be easy to calculate the natural frequencies $\omega$ through Fourier transformation.

For an n-freedom system, the free decay signals are composed of $n$ natural frequencies theoretically. But practically a lot of natural frequencies will be missing, and only several apparent frequencies can be measured and identified. How many and which frequencies can be identified from the testing data depend mainly on the properties of excitation, position of sensors, and so on [14-17]. For measuring the overall low-frequency vibration of the excavator boom, the excitation of initial displacement must be exerted on the whole boom rather than local part. Moreover, the excitation of initial displacement must be powerful enough to excite the overall low-frequency vibration of the boom, so that the signals from the sensor are easy to identify.

2.2. Excitation Strategy. The bucket wheel excavator DQLZ 1200 which is manufactured by Tidfore Heavy Industry Co., Ltd., of China, is used for natural frequency testing. The excavator DQLZ 1200 is 43 meters tall, 1260 tons in total, and theoretical capacity is $7200 \mathrm{~m}^{3}$ of bulk material. The bucked wheel boom, which is very important for the excavating operation, is a complex welded structure made up of numerous plates and beams. It weighs up to eighty tons and sixty meters of length, and the vibration in work process is primary low frequency $[18,19]$. For the low-frequency vibration testing of this kind of huge structure, the difficulty is providing suitable external excitations $[20,21]$. It would be advantageous provided that suitable excitation can be obtained from the internal of the machine rather than from outside. There are three potential internal excitations which are the motor with rotation of $24.7 \mathrm{~Hz}$, bucket wheel with rotation of $0.1 \mathrm{~Hz}$, and the belt-supporting rollers with rotation of $6.67 \mathrm{~Hz}$, respectively. Among these three excitations, the belt-supporting rollers are the most suitable as a low-frequency vibration exciter because there are many rollers arrayed along the whole long boom (Figure 1), so that it is powered enough to excite the overall structure vibration. Also, its rotation speed of $6.67 \mathrm{~Hz}$ is the most proximate to the low natural frequency of the boom.

\section{Test Process}

In this paper, the rotation of the belt-supporting rollers is tried as the exciter for low-frequency vibration testing, and the experiment is designed as Figure 2. Bruel and Kjaer vibration test and analysis system 3550 with 24 channels are adopted, and there are totally five accelerometers with sensitivity of $100 \mathrm{mV} / \mathrm{g}$ mounted on the boom. Two sensors are mounted on the distal end of the boom for gathering $y$ direction acceleration signals, and the other two are mounted on the near end of the boom for gathering $y$ - and $z$ direction acceleration signals. The last sensor is mounted vertically on the diagonal bar for measuring the vertical vibration signal.

In a single test procedure, the bucket wheel starts to rotate at $5.8 \mathrm{rpm}$ when the bucket wheel motor is turned on. At this time, only a slight vibration can be felt. After a few seconds, the conveyor belt began to rotate at $400 \mathrm{rpm}$ $(6.67 \mathrm{~Hz})$, so that obvious vibration occurs during this period. After that, the belt conveyor and the bucket wheel motor are suddenly powered off, leaving the boom vibration decay freely until it stops completely. This test procedure is repeated three times, and the signals measured from the five sensors are shown in Figure 3.

\section{Test Results}

Figure 3(a) shows the in-time signal of acceleration measured by sensor No. 1. It clearly shows that the signal covers all the three periods which are the bucket wheel start period, belt conveyor start period, and the period of free decay after the sudden power off. Figure 3(b) shows the partial enlargement of the free decay period after the first power off. Obviously, the decay signal does not completely decrease to zero, and the free decay signal shows a distinctive characteristic of multifrequency vibration. For frequency identification, both the stable operation in-time signal and the free decay in-time signal are converted into the frequency domain by the fast Fourier transformation (FFT), and the transformed results are shown as Figures 3(c) and 3(d), respectively. Comparison of the two figures shows that the frequency of the stable running is very rich, which not only reflects the natural frequency of the boom but also reflects the motor rotation frequency $(24.7 \mathrm{~Hz})$ and the electrical noise frequency $(49.8 \mathrm{~Hz})$, while the free decay period consists of only four frequencies of $0.1,1.76,2.02$, and $2.56 \mathrm{~Hz}$. Since $0.1 \mathrm{~Hz}$ comes from the inertial rotation of the bucket wheel, the true natural frequencies of the boom are $1.76,2.02$, and $2.56 \mathrm{~Hz}$.

Signals captured by the other four sensors are treated similarly as the sensor No.1. Finally, five natural frequencies in total can be obviously identified from the five sensors. They are $0.51,0.74,1.78,2.02$, and $2.56 \mathrm{~Hz}$, respectively, which are listed in Table 1.

\section{Results Verification}

To verify the experiment results, in this paper, the finite element method is applied and a high precision FE model is 


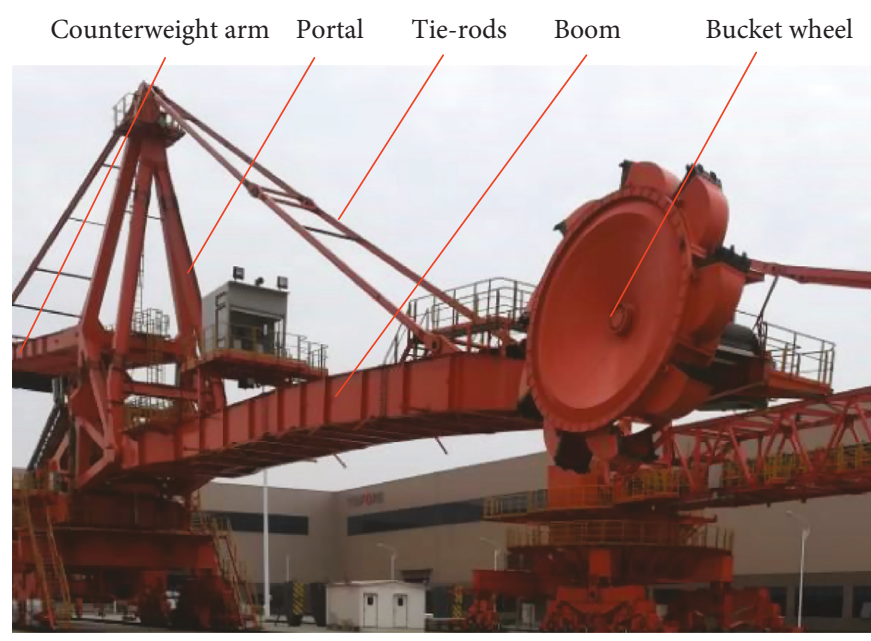

(a)

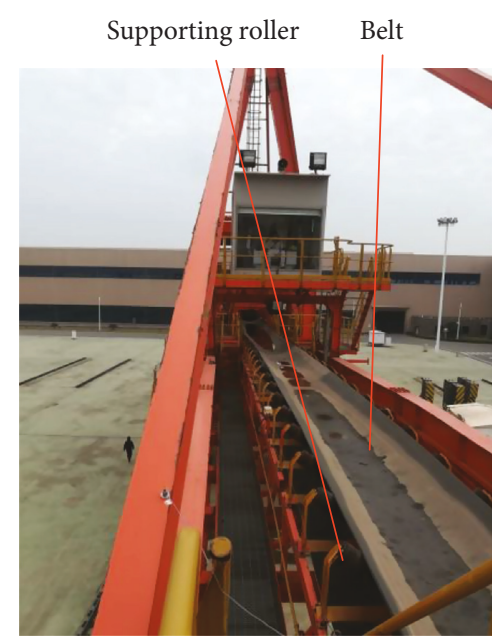

(b)

FIgURe 1: Bucket wheel excavator DQLZ 1200: (a) components and structures, (b) belt-supporting rollers.

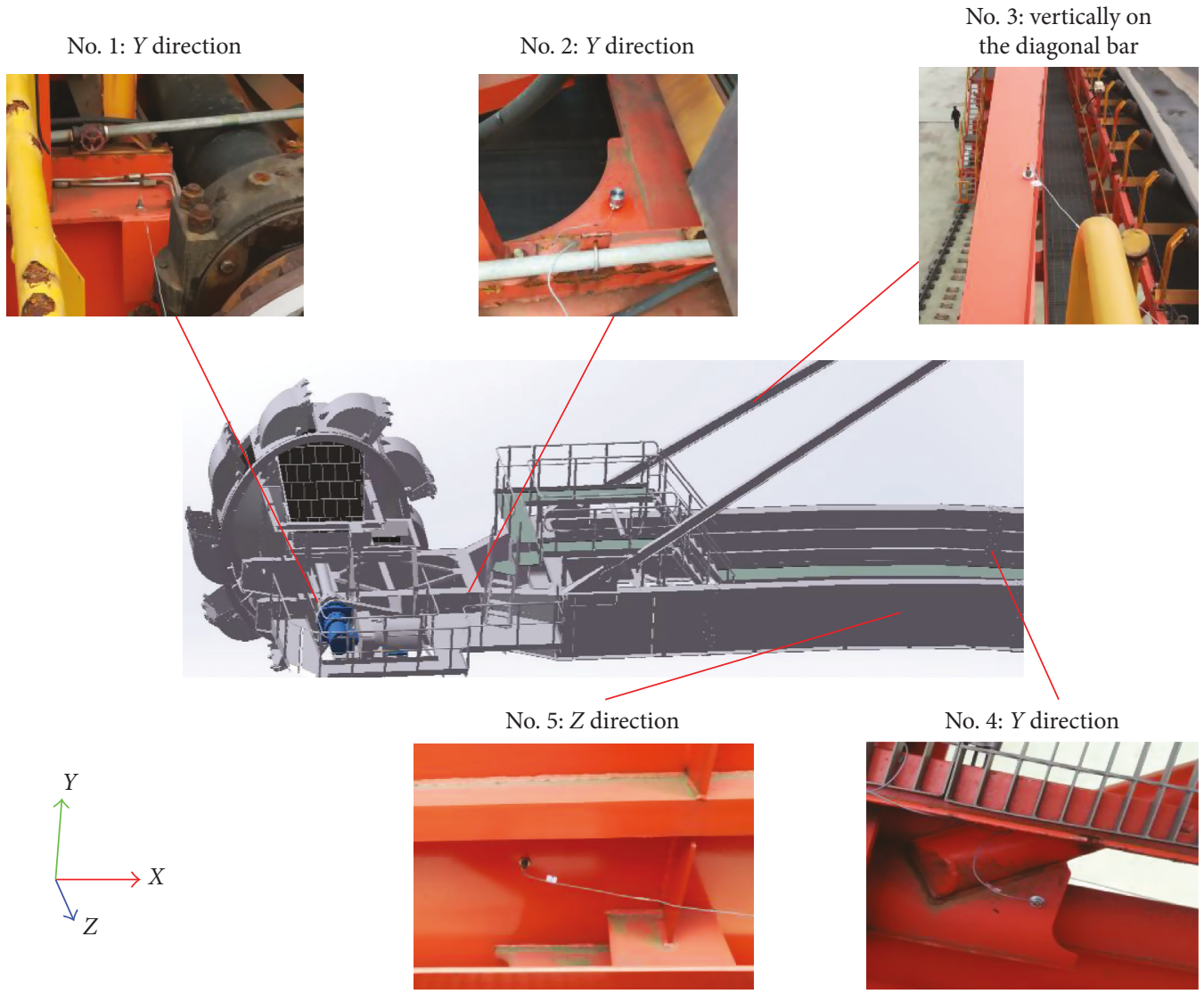

Figure 2: The positions of five accelerometers.

built for comparison. As for the powerful modeling capability, software HYPERMESH is chosen for the establishment and analysis of finite element model. For modal analysis, the key to high accuracy of the FE model depends on the similarity of the structure, mass, and stiffness between the model and the real object. Therefore, to make sure the accuracy of simulation model, the weight, shape, and structure of each component are strictly built to maximize consistency with the tested wheel excavator. For simplification, the pin supports are treated as rotational free beam elements with the same stiffness and mass; hydraulic cylinder and suspensions are treated as spring and damping 


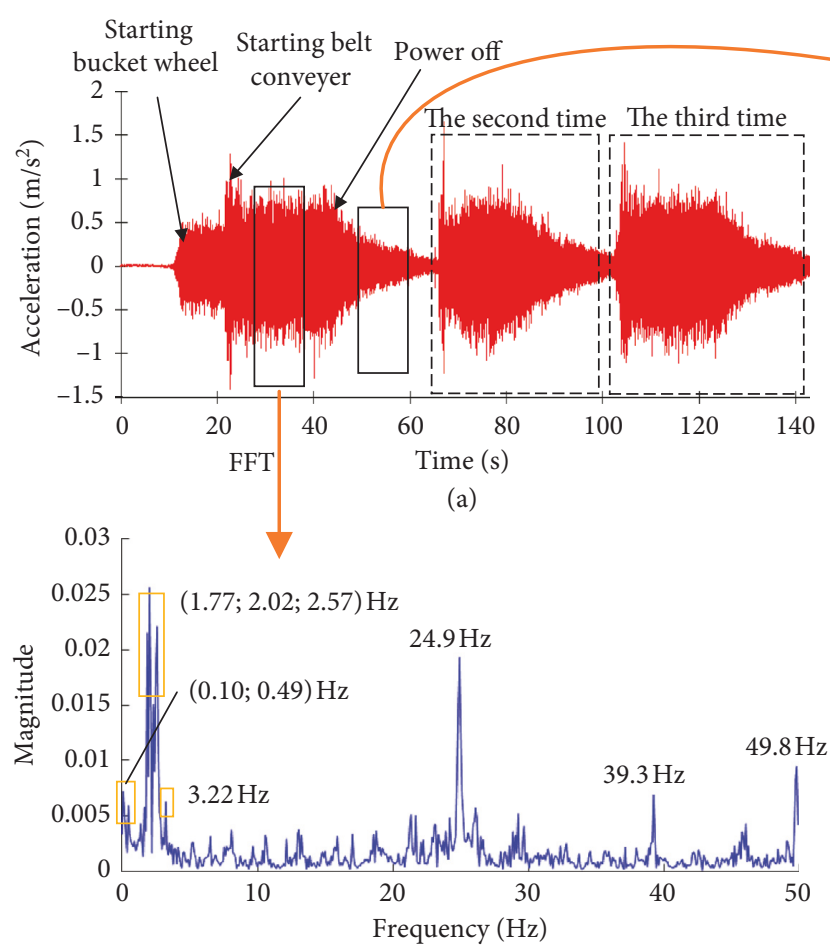

(c)

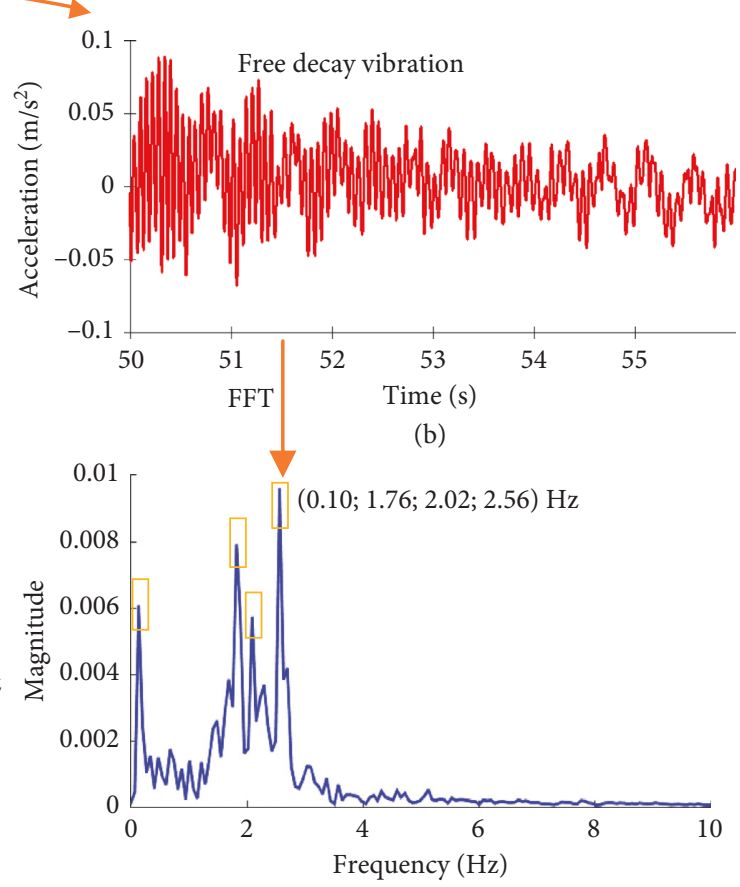

(d)

FIgURE 3: Testing results. (a) Signal of acceleration measured by sensor no. 1, (b) partial enlargement of the free decay period, (c) FFT results of the stable operation period, and (d) FFT results of the free decay period.

TABLE 1: Measured natural frequencies.

\begin{tabular}{lccccc}
\hline Frequencies $(\mathrm{Hz})$ & 0.51 & 0.74 & 1.78 & 2.02 & 2.56 \\
\hline Axes & $x, y, z$ & $z$ & $x, y, z$ & $x, y, z$ & $x, y, z$ \\
\hline
\end{tabular}

elements with the same stiffness and damping. After the process of geometric cleaning, midsurface extraction, meshing, mesh quality control, and so on, the finished highquality simplified finite element model with mixed element types is obtained and is shown in Figure 4(b).

In this study, the block Lanczos method is used for solving the dynamic equations, and the solved results consist of the first thirty natural frequencies and the corresponding vibration forms, in which nine modes in total are concerned with the overall vibration of the excavator boom, listed in Table 2. For comparison with the tested results, the first five simulated natural frequencies and corresponding vibration forms are presented in Figure 5. It clearly shows that all the five tested frequencies correspond fairly closely with the simulated results. These prove that the test method proposed in this paper is very accurate.

\section{Conclusion}

This paper aims to provide a better alternative method to test the low-frequency vibration of the huge bucket wheel excavator. Since the difficulty of testing is providing effective and powerful excitation, the strategy that uses the

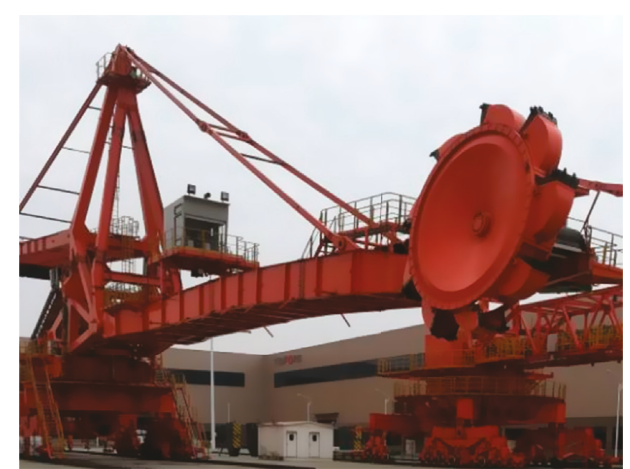

(a)

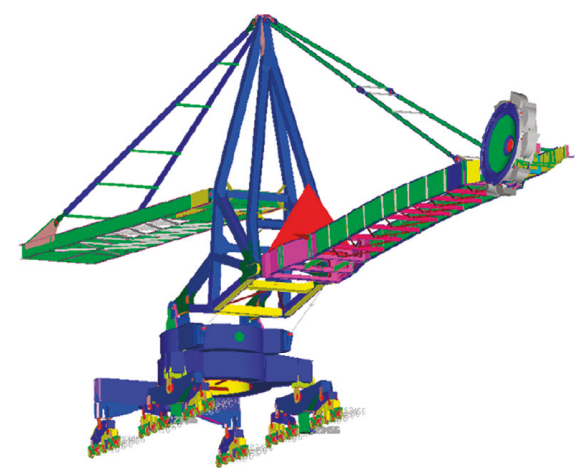

(b)

FIGURE 4: Structure of bucket wheel excavator: (a) real bucket wheel excavator, and (b) finite element model. 
TABLE 2: Selected simulated natural frequencies.

\begin{tabular}{lcc}
\hline Mode & Frequency & Vibration form \\
\hline 1 & 0.499 & Overall $y$-direction swing \\
2 & 0.725 & Overall $z$-direction swing \\
3 & 1.054 & Overall $x$-axis rotation \\
4 & 1.761 & $x$-axis torsion \\
5 & 1.982 & Overall $y$-axis rotation \\
6 & 2.535 & Overall $z$-axis rotation \\
7 & 2.831 & Overall $y$-direction bending \\
8 & 3.079 & Overall $z$-direction bending \\
9 & 3.848 & Coupled bending and torsion \\
\hline
\end{tabular}

Contour plot
Eigen mode (mag)

Analysis system

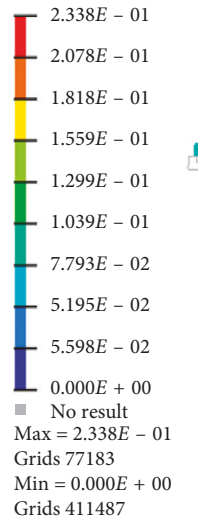

Grids 411487

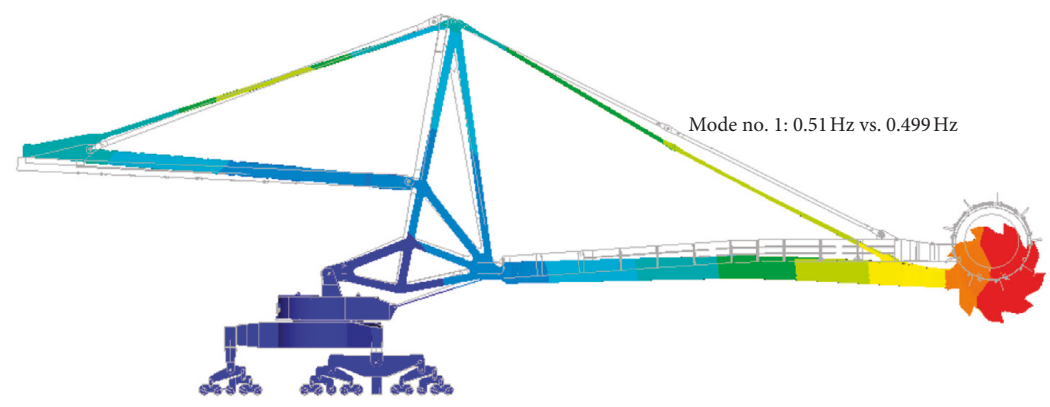

(a)

Contour plot Eigen mode (mag) Analysis system

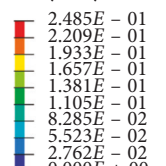
I $0.000 E+00$ $\operatorname{Max}=2.485 E-01$ Grids 81225 Min $=0.000 E+00$ Grids 411487

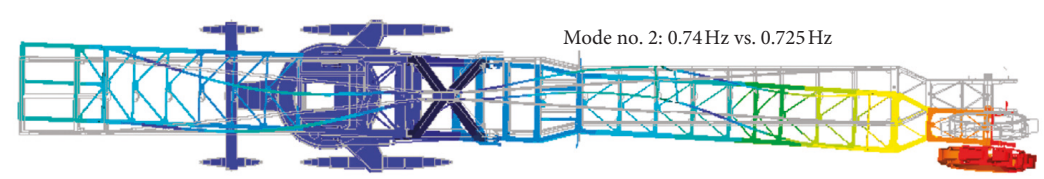

(b)

Contour plot Eigen mode (mag) Analysis system

T $\begin{aligned} & 5.008 E-01 \\ & 4.452 E-01\end{aligned}$

$-3.895 E-01$

$-3.339 E-01$

- $2.782 E-01$

$-2.226 E-01$

$-1.669 E-01$

$1.113 E-01$

$5.565 E-02$

$0.000 E+00$

- No result

$\operatorname{Max}=5.008 E-01$

Grids 69097

$\operatorname{Min}=0.000 E+00$

Grids 411487

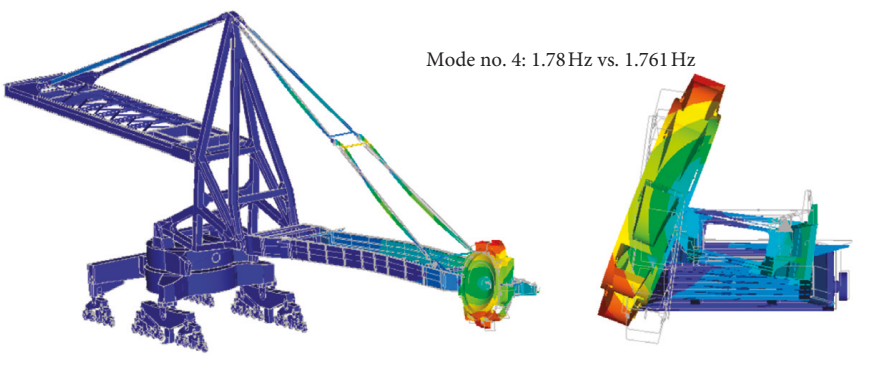

(c)

Figure 5: Continued. 


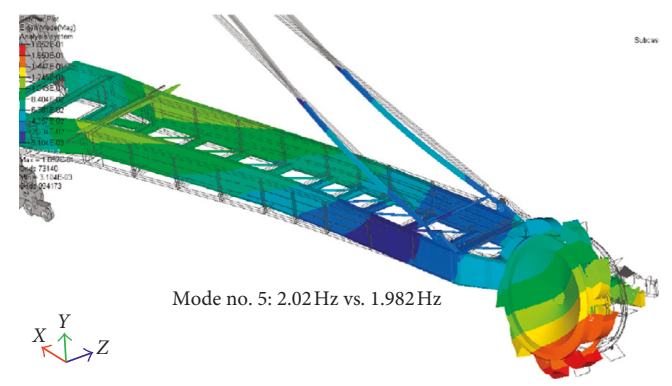

(d)

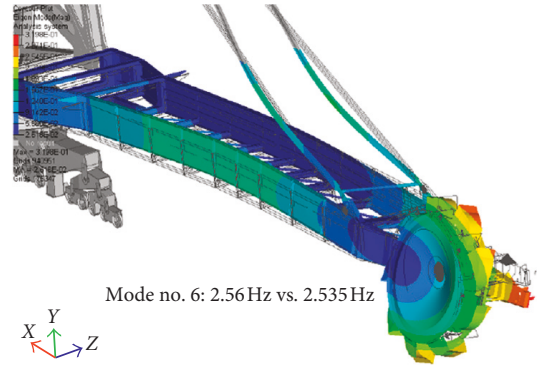

(e)

Figure 5: Comparison of results: (a) mode no. 1-overall $y$-direction swing; (b) mode no. 2-overall $z$-direction swing; (c) mode no. 4- $x$-axis torsion; (d) mode no. 5-overall $y$-axis rotation; (e) mode no. 6-overall $z$-axis rotation.

belt-supporting rollers on the boom as exciter is tried. The results show that the proposed method is quite simple as well as accurate for obtaining low natural frequencies of the bucked wheel excavator. The detailed conclusions can be summed as follows:

(1) As there is no need for adding extra devices, the proposed method is much simpler and costs low compared to previous low natural frequencies testing methods which obtained the frequencies through the signals caused by the sudden free of initial displacement.

(2) Since the bucket wheel excavator is a structure of vast bulk and great mass, the difficulty of low-frequency vibration testing is providing effective and powerful excitation. In this paper, the rotation of beltsupporting rollers is proposed as the excitation, and it is proved that it is very suitable and powerful enough for exciting the low-frequency vibration.

(3) By starting the belt-supporting rollers and suddenly powering off, it is convenient to obtain the stepdecay signal which is composed of stable running and free decay vibration period. Fast Fourier transform results show that the frequency of the stable running is richer than the free decay period.

(4) The measured five natural frequencies by the proposed method are, respectively, $0.51,0.74,1.78,2.02$, and $2.56 \mathrm{~Hz}$, while the corresponding frequencies of the simulation are $0.499,0.725,1.761,1.982$, and $2.533 \mathrm{~Hz}$. This proves the proposed testing method can achieve the same accuracy, but is much more convenient and costs less.

\section{Data Availability}

The data used to support the findings of this study are available from the corresponding author upon request.

\section{Conflicts of Interest}

The authors declare that they have no conflicts of interest.

\section{Acknowledgments}

This study was funded by the National Natural Science Foundation of China (no. 51705143), Hunan Provincial Natural Science Foundation (no. 2018JJ3164 and 2017JJ1015).

\section{References}

[1] S. M. Bošnjak, M. A. Arsić, N. B. Gnjatović, I. L. J. Milenović, and D. M. Arsić, "Failure of the bucket wheel excavator buckets," Engineering Failure Analysis, vol. 84, pp. 247-261, 2018.

[2] D. Djurdjevic, T. Maneski, V. M. Mitic, N. Andjelic, and D. Ignjatovic, "Failure investigation and reparation of a crack on the boom of the bucket wheel excavator ERS 1250 Gacko," Engineering Failure Analysis, vol. 92, pp. 301-316, 2018.

[3] D. Danicic, S. Sedmak, D. Ignjatovic, and S. Mitrovic, "Bucket wheel excavator damage by fatigue fracture-case study," Procedia Materials Science, vol. 3, pp. 1723-1728, 2014.

[4] S. M. Bošnjak, S. D. Savićević, N. B. Gnjatović, I. L. J. Milenović, and M. P. Pantelić, "Disaster of the bucket wheel excavator caused by extreme environmental impact: consequences, rescue and reconstruction," Engineering Failure Analysis, vol. 56, pp. 360-374, 2015.

[5] E. Rusiński, P. Harnatkiewicz, M. Kowalczyk, and P. Moczko, "Examination of the causes of a bucket wheel fracture in a bucket wheel excavator," Engineering Failure Analysis, vol. 17, no. 6, pp. 1300-1312, 2010.

[6] M. Savković, M. Gašić, D. Petrović, N. Zdravković, and R. Pljakić, "Analysis of the drive shaft fracture of the bucket wheel excavator," Engineering Failure Analysis, vol. 20, pp. 105-117, 2012.

[7] E. Rusiński, M. Kowalczyk, P. Odyjas, and D. Pietrusiak, "Investigations of structural vibrations problems of high performance machines," FME Transactions, vol. 41, pp. 305310, 2013.

[8] A. Đ. Brkić, T. Maneski, D. Ignjatović, P. D. Jovančić, and V. K. S. Brkić, "Diagnostics of bucket wheel excavator discharge boom dynamic performance and its reconstruction," Eksploatacja i Niezawodnosc-Maintenance and Reliability, vol. 16, pp. 188-197, 2014.

[9] S. Bošnjak, N. Zrnić, and D. Oguamanam, "On the dynamic modeling of bucket wheel excavators," FME Transactions, vol. 34, pp. 221-226, 2006.

[10] E. Rusiński, J. Czmochowski, P. Moczko, and D. Pietrusiak, "Assessment of the correlation between the numerical and 
experimental dynamic characteristics of the bucket wheel excavator in terms of the operational conditions," FME Transactions, vol. 41, pp. 298-304, 2013.

[11] E. Rusinski, S. Dragan, P. Moczko, and D. Pietrusiak, "Implementation of experimental method of determining modal characteristics of surface mining machinery in the modernization of the excavating unit," Archives of Civil and Mechanical Engineering, vol. 12, no. 4, pp. 471-476, 2012.

[12] J. Wang, G. Zhang, X. Gao, and T. Kong, "Dynamic response of bucket wheel stacker/reclaimer under head shock excitation," Hoisting and Conveying Machinery, vol. 1, pp. 8-10, 2012.

[13] J. Gottvald, "Measuring and comparison of natural frequencies of bucket wheel excavators SchRs 1320 and K 2000," in Proceedings of Wseas International Conference on Energy and Develepment-Environment-Biomedicine, pp. 335-340, Corfu Island, Greece, July 2011.

[14] A. Bajrić and J. Høgsberg, "Identification of damping and complex modes in structural vibrations," Journal of Sound and Vibration, vol. 431, pp. 367-389, 2018.

[15] J. H. Kang, "Viscously damped free and forced vibrations of circular and annular membranes by a closed form exact method," Thin-Walled Structures, vol. 116, pp. 194-200, 2017.

[16] J. M. Ramírez, C. D. Gatti, S. P. Machado, and M. Febbo, "A multi-modal energy harvesting device for low-frequency vibrations," Extreme Mechanics Letters, vol. 22, pp. 1-7, 2018.

[17] L. E. Thanh Danh and N. Vu Anh Duy, "Low-frequency vibration isolator with adjustable configurative parameter," International Journal of Mechanical Sciences, vol. 134, pp. 224-233, 2017.

[18] J. Gottvald, "The calculation and measurement of the natural frequencies of the bucket wheel excavator SchRs 1320/4x30," Transport, vol. 25, no. 3, pp. 269-277, 2010.

[19] D. Pietrusiak, T. Smolnicki, and M. Stanńco, "The influence of superstructure vibrations on operational loads in the undercarriage of bulk material handling machine," Archives of Civil and Mechanical Engineering, vol. 17, no. 4, pp. 855-862, 2017.

[20] P. D. Jovančić, D. Ignjatović, M. Tanasijević, and T. Maneski, "Load-bearing steel structure diagnostics on bucket wheel excavator, for the purpose of failure prevention," Engineering Failure Analysis, vol. 18, no. 4, pp. 1203-1211, 2011.

[21] X. J. Zhao and C. Schindler, "Evaluation of whole-body vibration exposure experienced by operators of a compact wheel loader according to ISO 2631-1:1997 and ISO 2631-5:2004," International Journal of Industrial Ergonomics, vol. 44, no. 6, pp. 840-850, 2014. 


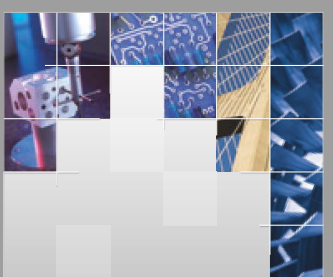

\section{Enfincering}
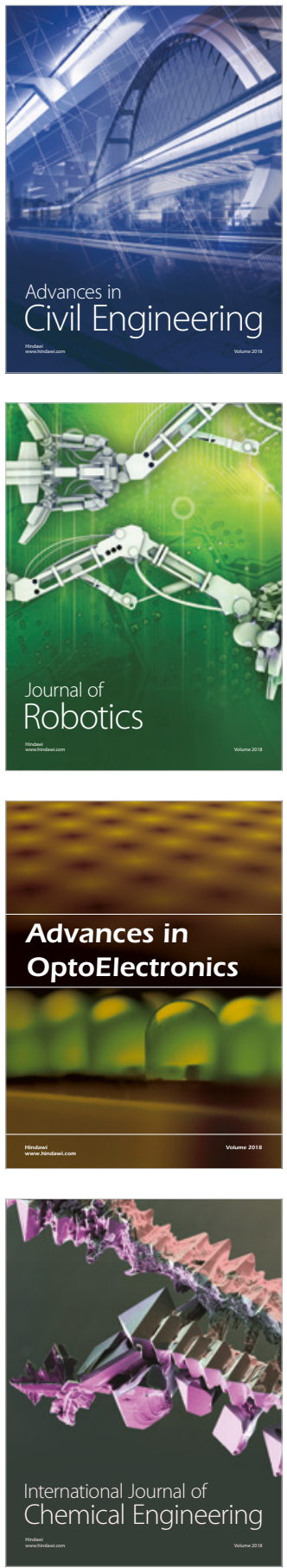

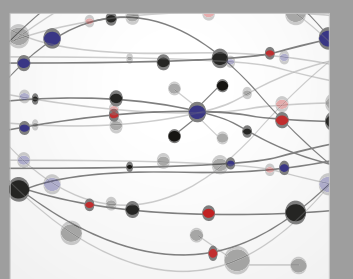

\section{Rotating \\ Machinery}

The Scientific World Journal

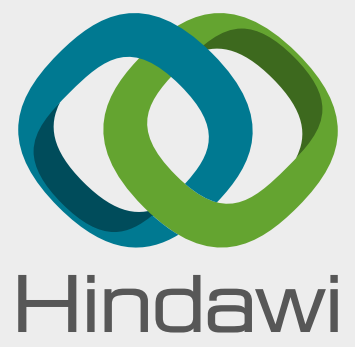

Submit your manuscripts at

www.hindawi.com
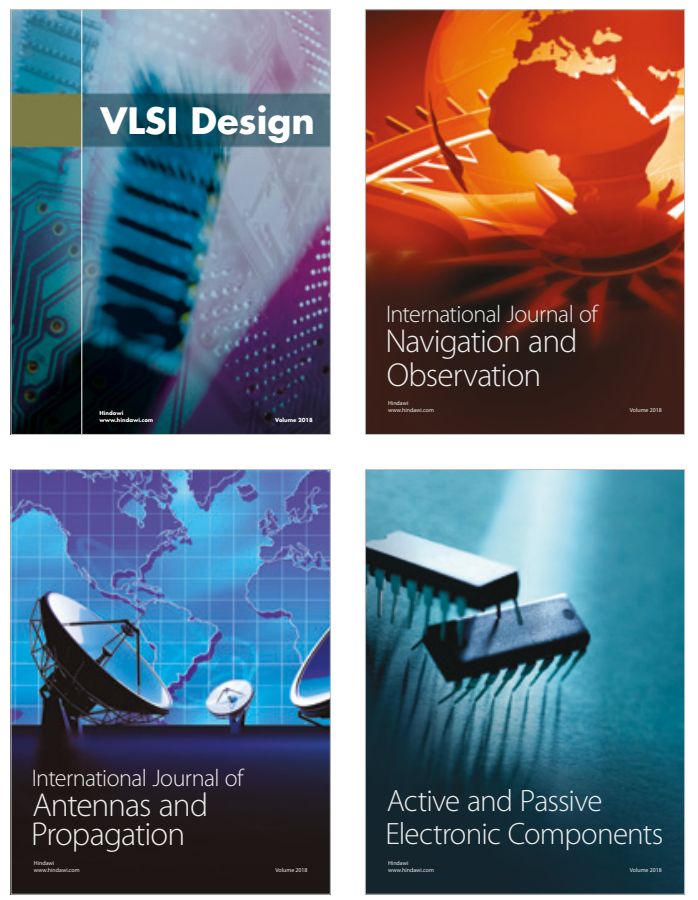
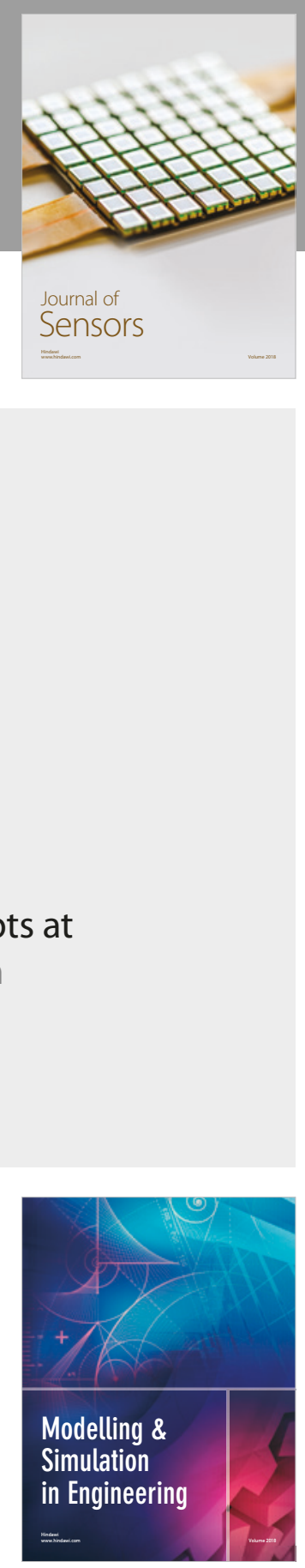

\section{Advances \\ Multimedia}
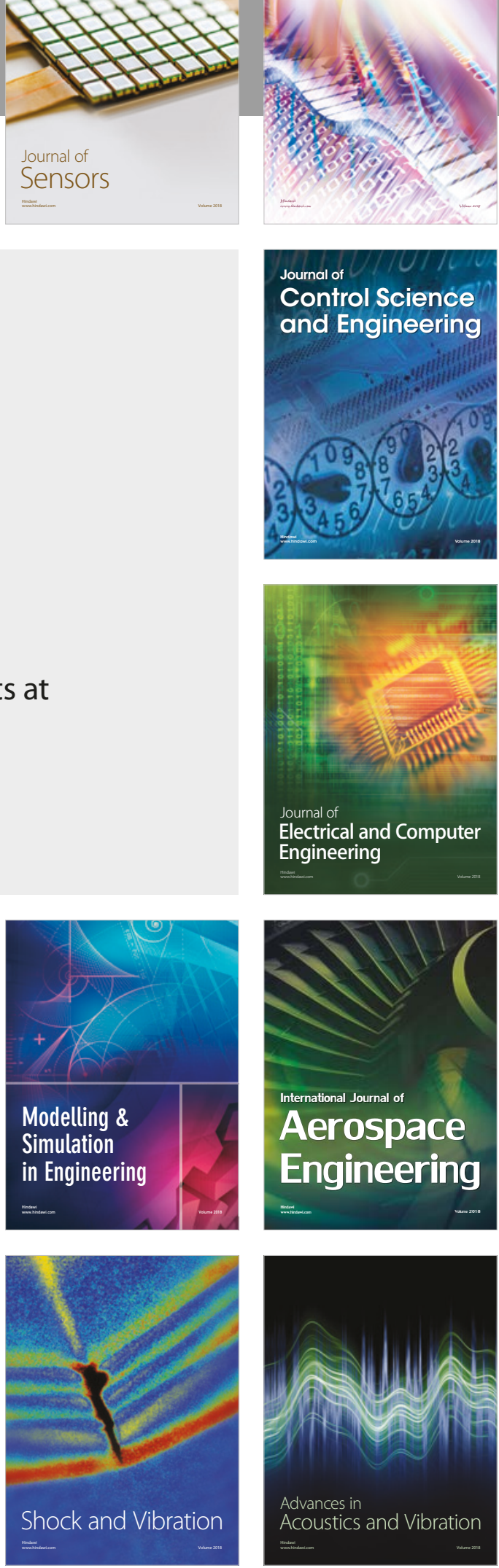